Article

\title{
A Comparison of In-House Real-Time LAMP Assays with a Commercial Assay for the Detection of Pathogenic Bacteria
}

\author{
Deguo Wang ${ }^{1}$, Yongzhen Wang ${ }^{2}$, Fugang Xiao ${ }^{1}$, Weiyun Guo ${ }^{1}$, Yongqing Zhang ${ }^{1}$, \\ Aiping Wang ${ }^{3}$ and Yanhong Liu ${ }^{4, *}$
}

1 Henan Postdoctoral Research Base, Food and Bioengineering College, Xuchang University, Xuchang 461000, Henan, China; E-Mails: wangdg666@126.com (D.W.); xfug@163.com (F.X.); gwy2002@126.com (W.G.); zyq336@163.com (Y.Z.)

2 Public Lab Center, Xuchang University, Xuchang 461000, Henan, China;

E-Mail: wangyzhxuch@sina.com

3 Life Science College, Zhengzhou University, Zhengzhou 450000, Henan, China;

E-Mail: pingaw@126.com

4 Molecular Characterization of Foodborne Pathogens Research Unit, Eastern Regional Research Center, Agricultural Research Service, United States Department of Agriculture, Wyndmoor, PA 19038, USA

* Author to whom correspondence should be addressed; E-Mail: yanhong.liu@ars.usda.gov; Tel.: +1-215-233-6587; Fax: +1-215-233-6581.

Academic Editor: Derek J. McPhee

Received: 12 April 2015 / Accepted: 20 May 2015 / Published: 25 May 2015

\begin{abstract}
Molecular detection of bacterial pathogens based on LAMP methods is a faster and simpler approach than conventional culture methods. Although different LAMP-based methods for pathogenic bacterial detection are available, a systematic comparison of these different LAMP assays has not been performed. In this paper, we compared 12 in-house real-time LAMP assays with a commercialized kit (Isothermal Master Mix) for the detection of Listeria monocytogenes, Salmonella spp, Staphylococcus aureus, Escherichia coli O157, E. coli O26, E. coli O45, E. coli O103, E. coli O111, E. coli O121, E. coli $\mathrm{O} 145$ and Streptococcus agalactiae. False-positive results were observed in all 12 in-house real-time LAMP assays, while all the negative controls of Isothermal Master Mix remained negative after amplification. The detection limit of Isothermal Master Mix for Listeria monocytogenes, Salmonella spp, Staphylococcus aureus, Escherichia coli O157, E. coli O26, E. coli O45, E. coli $\mathrm{O} 103$, E. coli $\mathrm{O} 111$, E. coli $\mathrm{O} 121$ and Streptococcus agalactiae was 1 pg, whereas
\end{abstract}


the sensitivity of the commercialized kit for E. coli $\mathrm{O} 145$ was $100 \mathrm{pg}$. In conclusion, the 12 in-house real-time LAMP assays were impractical to use, while the commercialized kit Isothermal Master Mix was useful for the detection of most bacterial pathogens.

Keywords: real-time loop-mediated isothermal amplification (LAMP); specificity; sensitivity; pathogenic bacteria

\section{Introduction}

Loop-mediated isothermal amplification (LAMP), developed by Notomi et al. in 2000 [1], can specifically, sensitively and rapidly amplify nucleic acids utilizing a DNA polymerase enzyme with high strand displacement activity and two pairs of primers recognizing six independent sequences of a target gene under isothermal conditions. Moreover, Nagamine et al. in 2002 has advanced the method by incorporating forward loop primers that accelerate the LAMP reaction [2]. Due to the cost effectiveness and sensitivity of LAMP, this method has been widely applied to basic medical research in and environmental testing, as well as point-of-care testing and diagnosis of infectious diseases in clinical settings [3]. In addition, LAMP has also been applied for pathogen detection, and has successfully been used to detect Listeria monocytogenes [4], Salmonella, spp [5], Staphylococcus aureus [6], Escherichia coli $\mathrm{O} 157$ [7,8], E. coli O26 [7], E. coli O45 [7], E. coli $\mathrm{O} 103$ [7], E. coli O111 [7], E. coli O121 [7], Streptococcus agalactiae [9], Actinobacillus actinomycetemcomitans [10], Mycobacterium tuberculosis [11], and Streptococcus pneumonia [12]. However, a systematic evaluation of these different LAMP assays has not been performed.

The objective of the present study was to compare 12 in-house real-time LAMP assays for the detection of Listeria monocytogenes, Salmonella, Staphylococcus aureus, Escherichia coli O157, E. coli $\mathrm{O} 26$, E. coli $\mathrm{O} 45$, E. coli $\mathrm{O} 103$, E. coli $\mathrm{O} 111$, E. coli $\mathrm{O} 121$, E. coli $\mathrm{O} 145$ and Streptococcus agalactiae performed using previously described protocols [4-9] with a commercial kit (Isothermal Master Mix, OptiGene, Horsham, UK).

\section{Results and Discussion}

\subsection{Non-Specific Amplification}

After the negative controls without genomic DNA were kept at the described temperature for 50 min, false-positive results were observed among all 12 in-house real-time LAMP assays for detection of L. monocytogenes, Salmonella, Staphylococcus aureus, E. coli O157, E. coli O26, E. coli O45, E. coli O103, E. coli O111, E. coli $\mathrm{O} 121$ and Streptococcus agalactiae, while all negative controls of the commercial kit Isothermal Master Mix remained negative after amplification at $65{ }^{\circ} \mathrm{C}$ for $50 \mathrm{~min}$, as indicated in Table 1. The cross pollution caused by DNA templates as well as amplified products of the LAMP reactions had been excluded, therefore, the non-specific amplification of 12 in-house real-time LAMP assays could be caused by primer dimers, in contrast, the commercial assay can be free of such non-specific amplification. 
Table 1. Results of non-specific amplification determination from in-house real-time LAMP assay and the isothermal master mix kit.

\begin{tabular}{|c|c|c|}
\hline Bacterial Strains (Gene) & Assay & $\begin{array}{c}\text { No. LAMP-Positive/No. of } \\
\text { Total Experiments Carried Out }\end{array}$ \\
\hline \multirow{2}{*}{ Listeria monocytogenes (hly $\mathrm{A})$} & In-house Real-time LAMP Assay & $3 / 3$ \\
\hline & Isothermal Master Mix & $0 / 3$ \\
\hline \multirow{2}{*}{ Salmonella $\operatorname{spp}($ invA) } & In-house Real-time LAMP Assay & $2 / 3$ \\
\hline & Isothermal Master Mix & $0 / 3$ \\
\hline \multirow{2}{*}{ Staphylococcus aureus (nuc) } & In-house Real-time LAMP Assay & $3 / 3$ \\
\hline & Isothermal Master Mix & $0 / 3$ \\
\hline \multirow{2}{*}{ Escherichia coli $\mathrm{O} 157$ (rfbE) } & In-house Real-time LAMP Assay & $1 / 3$ \\
\hline & Isothermal Master Mix & $0 / 3$ \\
\hline \multirow{2}{*}{ Escherichia coli $\mathrm{O} 26$ (wzy) } & In-house Real-time LAMP Assay & $3 / 3$ \\
\hline & Isothermal Master Mix & $0 / 3$ \\
\hline \multirow{2}{*}{ Escherichia coli $\mathrm{O} 45$ (wzy) } & In-house Real-time LAMP Assay & $3 / 3$ \\
\hline & Isothermal Master Mix & $0 / 3$ \\
\hline \multirow{2}{*}{ Escherichia coli $\mathrm{O} 103(w z x)$} & In-house Real-time LAMP Assay & $1 / 3$ \\
\hline & Isothermal Master Mix & $0 / 3$ \\
\hline \multirow{2}{*}{ Escherichia coli $\mathrm{O} 111$ (wzy) } & In-house Real-time LAMP Assay & $2 / 3$ \\
\hline & Isothermal Master Mix & $0 / 3$ \\
\hline \multirow{2}{*}{ Escherichia coli $\mathrm{O} 121$ (wzy) } & In-house Real-time LAMP Assay & $2 / 3$ \\
\hline & Isothermal Master Mix & $0 / 3$ \\
\hline \multirow{2}{*}{ Escherichia coli $\mathrm{O} 145$ (wzx) } & In-house Real-time LAMP Assay & $3 / 3$ \\
\hline & Isothermal Master Mix & $0 / 3$ \\
\hline \multirow{2}{*}{ Escherichia coli $\mathrm{O} 157$ (wzy) } & In-house Real-time LAMP Assay & $3 / 3$ \\
\hline & Isothermal Master Mix & $0 / 3$ \\
\hline \multirow{2}{*}{ Streptococcus agalactiae (sobA) } & In-house Real-time LAMP Assay & $2 / 3$ \\
\hline & Isothermal Master Mix & $0 / 3$ \\
\hline
\end{tabular}

\subsection{Sensitivity of the Commercial Assay}

Because of the serious non-specific amplification, determining the detection limits of the 12 in-house real-time LAMP assays was of no practical significance, and only the sensitivity of the commercial Isothermal Master Mix kit for pathogenic bacteria detection was determined.

As Table 2 indicates, the detection limit of Isothermal Master Mix for Listeria monocytogenes, Salmonella spp, Staphylococcus aureus, Escherichia coli O157, E. coli O26, E. coli O45, E. coli O103, E. coli $\mathrm{O} 111$, E. coli $\mathrm{O} 121$ and Streptococcus agalactiae was $1 \mathrm{pg}$. However, all reactions with serial dilutions of E. coli O145 DNA template ranging from 0.1-100 pg were negative, and then we repeated the experiment, one of four reactions with $100 \mathrm{pg}$ E. coli O145 DNA template was positive (data not shown), therefore, the LAMP assay with the commercial kit Isothermal Master may not suitable for detection of some pathogenic bacteria because of the low sensitivity. 
Table 2. Sensitivity of real-time LAMP assays with the Isothermal Master Mix Kit.

\begin{tabular}{|c|c|c|c|c|}
\hline Bacterial Strains (Gene) ${ }^{a}$ & $\begin{array}{c}10 \text { pg DNA } \\
\text { Template }\end{array}$ & $\begin{array}{l}1 \text { pg DNA } \\
\text { Template }\end{array}$ & $\begin{array}{c}\text { 0.1 pg DNA } \\
\text { Template }\end{array}$ & $\begin{array}{l}\text { Negative } \\
\text { Controls }\end{array}$ \\
\hline Listeria monocytogenes ATCC19115 (hlyA) & $4 / 4$ & $4 / 4$ & $0 / 4$ & $0 / 4$ \\
\hline Salmonella enterica serotype Newport (invA) & $4 / 4$ & $4 / 4$ & $0 / 4$ & $0 / 4$ \\
\hline Staphylococcus aureus ATCC 25923 (nuc) & $4 / 4$ & $4 / 4$ & $0 / 4$ & $0 / 4$ \\
\hline Escherichia coli $\mathrm{O} 157: \mathrm{H} 7933$ (rfbE) & $4 / 4$ & $4 / 4$ & $0 / 4$ & $0 / 4$ \\
\hline Escherichia coli $\mathrm{O} 26: \mathrm{H} 11$ (wzy) & $4 / 4$ & $3 / 4$ & $1 / 4$ & $0 / 4$ \\
\hline Escherichia coli $\mathrm{O} 45: \mathrm{H} 12$ (wzy) & $4 / 4$ & $2 / 4$ & $0 / 4$ & $0 / 4$ \\
\hline Escherichia coli $\mathrm{O} 103: \mathrm{H} 2(w z x)$ & $4 / 4$ & $4 / 4$ & $0 / 4$ & $0 / 4$ \\
\hline Escherichia coli $\mathrm{O} 111: \mathrm{H} 8$ (wzy) & $4 / 4$ & $4 / 4$ & $0 / 4$ & $0 / 4$ \\
\hline Escherichia coli $\mathrm{O} 121: \mathrm{H} 19$ (wzy) & $4 / 4$ & $2 / 4$ & $0 / 4$ & $0 / 4$ \\
\hline Escherichia coli $\mathrm{O} 145: \mathrm{H} 2(w z x)$ & $1 / 8$ & $0 / 8$ & $0 / 8$ & $0 / 8$ \\
\hline Escherichia coli $\mathrm{O} 157: \mathrm{H} 7933$ (wzy) & $4 / 4$ & $4 / 4$ & $0 / 4$ & $0 / 4$ \\
\hline Streptococcus agalactiae ATCC 27956 (sobA) & $4 / 4$ & $4 / 4$ & $0 / 4$ & $0 / 4$ \\
\hline
\end{tabular}

a All these strains were obtained from the Food and Bioengineering College of Xuchang University, Henan, China.

\section{Experimental Section}

\subsection{LAMP Primers}

The described LAMP primers targeting specific genes of the hlyA of Listeria monocytogenes, invA of Salmonella, nuc of Staphylococcus aureus, rfbE of Escherichia coli O157, wzy of E. coli O26, wzy of E. coli $\mathrm{O} 45$, wzx of $E$. coli $\mathrm{O} 103$, wzy of E. coli O111, wzy of E. coli O121, wzx of E. coli O145, wzy of $r f b \mathrm{E}$ of E. coli $\mathrm{O} 157$ and sobA of Streptococcus agalactiae used in this study are shown in Table 3 [4-9].

Table 3. Primers of the 12 in-house real-time LAMP assays for bacterial pathogen detection.

\begin{tabular}{|c|c|c|c|c|}
\hline Bacterial Strains & Gene & Primer & Sequence (5'-3') & References \\
\hline \multirow{6}{*}{$\begin{array}{c}\text { Listeria } \\
\text { monocytogenes }\end{array}$} & \multirow{6}{*}{ hlyA } & LB & GCCAAGAAAAGGTTACAAAGATGG & \multirow{6}{*}{ [4] } \\
\hline & & LF & TAGGACTTGCAGGCGGAGATG & \\
\hline & & B3 & GCTTTTACGAGAGCACCTGG & \\
\hline & & F3 & TTGCGCAACAAACTGAAGC & \\
\hline & & BIP & CCACGGAGATGCAGTGACAAATGTTTTGGATTTCTTCTTTTTCTCCACAAC & \\
\hline & & FIP & CGTGTTTCTTTTCGATTGGCGTCTTTTTTTCATCCATGGCACCACC & \\
\hline \multirow{6}{*}{ Salmonella spp } & \multirow{6}{*}{$\operatorname{inv} \mathrm{A}$} & LB & GGGCAATTCGTTATTGGCGATAG & \multirow{6}{*}[5]{} \\
\hline & & LF & GACGAAAGAGCGTGGTAATTAAC & \\
\hline & & B3 & AACGATAAACTGGACCACGG & \\
\hline & & F3 & GGCGATATTGGTGTTTATGGGG & \\
\hline & & BIP & CCGGTGAAATTATCGCCACACAAAACCCACCGCCAGG & \\
\hline & & FIP & GACGACTGGTACTGATCGATAGTTTTTCAACGTTTCCTGCGG & \\
\hline \multirow{6}{*}{$\begin{array}{c}\text { Staphylococcus } \\
\text { aureus }\end{array}$} & \multirow{6}{*}{ nuc } & LB & CAAACCTAACAATACACATGAACA & \multirow{6}{*}[6]{} \\
\hline & & LF & ACGCTAAGCCACGTCCATAT & \\
\hline & & B3 & CGTTGTCTTCGCTCCAAAT & \\
\hline & & F3 & TGCAAAGAAAATTGAAGTCGA & \\
\hline & & BIP & TCAAGGCTTGGCTAAAGTTGCTTATTCGCTTGTGCTTCACTT & \\
\hline & & FIP & CGTTTACCATTTTTCCATCAGCATATTTGACAAAGGTCAAAGAACT & \\
\hline
\end{tabular}


Table 3. Cont.

\begin{tabular}{|c|c|c|c|c|}
\hline Bacterial Strains & Gene & Primer & Sequence (5'-3') & References \\
\hline \multirow{4}{*}{$\begin{array}{l}\text { Escherichia coli } \\
\text { O157 }\end{array}$} & \multirow{4}{*}{$r f b \mathrm{E}$} & B3 & GGTGCTTTTGATATTTTTCCG & \multirow{4}{*}{ [7] } \\
\hline & & F3 & AACAGTCTTGTACAAGTCCA & \\
\hline & & BIP & СТCTCTTTCCTCTGCGGTCC-GATGTTTTTCACACTTATTGGAT & \\
\hline & & FIP & TAAGGAATCACCTTGCAGATAAACT-AGTACATTGGCATCGTGT & \\
\hline \multirow{6}{*}{$\begin{array}{c}\text { Escherichia coli } \\
\text { O26 }\end{array}$} & \multirow{6}{*}{$w z y$} & LB & TACAATACAGTAAGTATACAGCATT & \multirow{6}{*}{ [8] } \\
\hline & & LF & ACCAGCGATAACCAATCTC & \\
\hline & & B3 & TCCTGATTTGAACAATGTCAAT & \\
\hline & & F3 & GACTATGAAGCGTATGTTGAT & \\
\hline & & BIP & TTCCTTGGGACCACATTCCT-ACATGTAAAGCAGCAAACC & \\
\hline & & FIP & ACCGCCTAAATACTTAACACCATAA-TTAATGTCAATGAACTTTATGCC & \\
\hline \multirow{5}{*}{$\begin{array}{l}\text { Escherichia coli } \\
\text { O45 }\end{array}$} & \multirow{5}{*}{$w z y$} & LB & TTATTACTCCTGGCAGTATTAATCG & \multirow{5}{*}{ [8] } \\
\hline & & B3 & TTTAGTCGCTCGCCAAGA & \\
\hline & & F3 & AATGTCCCCAGGGTTTGT & \\
\hline & & BIP & AGCGGGCTAATATTAGTAGTCACTC-GTATGCTTCAATTTGGCTGT & \\
\hline & & FIP & ACTCTGGGTTTGATTTTTTCACTTC-ATAATTTCATCCAGACGAACG & \\
\hline \multirow{6}{*}{$\begin{array}{l}\text { Escherichia coli } \\
\mathrm{O} 103\end{array}$} & \multirow{6}{*}{$w z x$} & LB & CCTTTATAAATGGATTCATTTCATC & \multirow{6}{*}{ [8] } \\
\hline & & LF & AATTGCAACAACTTTTGAAATAA & \\
\hline & & B3 & TCACCTTGATTTTCTGCTGA & \\
\hline & & F3 & ACTCAGTGGTGTAGTAACATG & \\
\hline & & BIP & TTGGGACAATTGCAAAATTTTGTGG-ATCTATTAACTCCTTGTGAAACTTG & \\
\hline & & FIP & ATTTGCTATTCCAATTGGACCAGTA-CTTTAGACTAATTTGTGGCCTTC & \\
\hline \multirow{5}{*}{$\begin{array}{c}\text { Escherichia coli } \\
\text { O111 }\end{array}$} & \multirow{5}{*}{$w z y$} & LB & CTTAAATAACGGCGGACAAT & \multirow{5}{*}{ [8] } \\
\hline & & B3 & TCATGAGGGTCATTAGGAATT & \\
\hline & & F3 & AAGGCGTAACTTTTTTTGAAC & \\
\hline & & BIP & TCCATGGTATGGGGACATTAAATTT-TGATGGAAGTCCATATAACGT & \\
\hline & & FIP & TCACCAAGCTGTGAAACCAAA-CTACAGCAAGTAATATTGAACGT & \\
\hline \multirow{5}{*}{$\begin{array}{l}\text { Escherichia coli } \\
\text { O121 }\end{array}$} & \multirow{5}{*}{$w z y$} & LF & TAAAGCCATCCAACCACGC & \multirow{5}{*}{ [8] } \\
\hline & & B3 & ATAGGCTCCCAACCATCC & \\
\hline & & F3 & GCTCAGCTTTTATCTTGTTCAA & \\
\hline & & BIP & TGTTGCTGGTTCCTTATTATGTAGT-AAAAGCAAGCCAAAACACTC & \\
\hline & & FIP & ACGCAAAAAGTATGGATTCATACCT-GATATAACAGAACCGACTTGG & \\
\hline \multirow{5}{*}{$\begin{array}{l}\text { Escherichia coli } \\
\text { O145 }\end{array}$} & \multirow{5}{*}{$w z x$} & LF & TTCTTAAGTTCGGATACACTAGCA & \multirow{5}{*}{ [8] } \\
\hline & & B3 & GCATTGGTACAGACAGCTTTA & \\
\hline & & F3 & TTTGTAAGACAAGGTGTATGG & \\
\hline & & BIP & AGTGTGCTTGGAGTGGCTTA-CAATCCCAGTTTGTAATATCGC & \\
\hline & & FIP & CACAGTACCACCAAACCAAAAAATA-TTGGTTAGCTATAGCTGTGA & \\
\hline \multirow{6}{*}{$\begin{array}{l}\text { Escherichia coli } \\
\text { O157 }\end{array}$} & \multirow{6}{*}{$w z y$} & LB & TCCTTTTCTCTCCGTATTGAT & \multirow{6}{*}{ [8] } \\
\hline & & LF & ATAATGATATATGAATAGAATGCGC & \\
\hline & & B3 & ATAACTGATATTTTCATTTCGTGAT & \\
\hline & & F3 & TCCCTTTAGGGATATATATACCTT & \\
\hline & & BIP & TTCCCAGCCACTAAGTATTGCAATATTTTTGAAAAAAACCCATAGCTCGA & \\
\hline & & FIP & TGCATCGGCCTTCTTTTTTGGTTTTAACGTATCATGCAATAAGATCA & \\
\hline
\end{tabular}


Table 3. Cont.

\begin{tabular}{ccccc}
\hline Bacterial Strains & Gene & Primer & Sequence (5'-3') & References \\
\hline \multirow{2}{*}{ Liseptococcus } & LB & AGGCGCTCTTAGCTGATGT \\
agalactiae & LF & B3 & TGCATGGTGCTTATCATGATGT & {$[9]$} \\
& F3 & ACCACCGTTATTGATGACTG & ATATGATGCGCTTGAGCC \\
& BIP & ACATCCTGAAATTGGAGAAGACTTTTTTCCTGACGAATATCTTCTGGAAT \\
& FIP & GAGCAGCATTTGCATTAGCAACATATTTTGATGCTGAGACAATGACAC & \\
\hline
\end{tabular}

\subsection{Determination of Non-Specific Amplification}

After the LAMP primers were synthesized by Sangon Biotech Co., Ltd (Shanghai, China), the non-specific amplification of the 12 in-house real-time LAMP assays as well as the commercial Isothermal Master Mix kit were determined via the corresponding negative controls with no genomic DNA. The experiment was performed before DNA extraction, therefore, cross pollution caused by DNA template as well as amplified products of LAMP reactions can be avoided, and the cause of false-positive results can be objectively judged.

The reaction mixtures and reaction conditions of the 12 in-house real-time LAMP assays were as described [4-9]. The $25 \mu \mathrm{L}$ in house reaction system contained $1.6 \mu \mathrm{mol} / \mathrm{L}$ of each of the inner primers FIP and BIP, $0.2 \mu \mathrm{mol} / \mathrm{L}$ of each of the outer primers F3 and B3, and $0.8 \mu \mathrm{mol} / \mathrm{L}$ of each of the loop primers LF and LB. $1.2 \mathrm{mmol} / \mathrm{L}$ each dNTP, $6 \mathrm{mmol} / \mathrm{L} \mathrm{MgSO}_{4}, 1 \times$ Bst DNA polymerase buffer (New England Biolabs, Beverly, MA, USA) $(20 \mathrm{mmol} / \mathrm{L}$ Tris- $\mathrm{HCl}(\mathrm{pH}=8.8), 10 \mathrm{mmol} / \mathrm{L} \mathrm{KCl}, 10 \mathrm{mmol} / \mathrm{L}$ $\left(\mathrm{NH}_{4}\right)_{2} \mathrm{SO}_{4}, 2 \mathrm{mmol} / \mathrm{L} \mathrm{MgSO}_{4}, 0.1 \%$ TritonX-100), 8 Units of Bst DNA large fragments (New England Biolabs). Depending on different experiments, $0 \mathrm{M}, 0.6 \mathrm{M}$ or 1.0 M of betaine (Sigma, St. Louis, MO, USA) were included, respectively. The LAMP assays were modified by adding $1 \times$ EvaGreen and $1 \times$ Rox, the experiment only on negative controls was carried out on StepOne ${ }^{\mathrm{TM}}$ System (Applied Biosystems, Foster City, CA, USA) at the described temperature $\left(65^{\circ} \mathrm{C}\right.$ for the invA of Salmonella, $r f b E$ of Escherichia coli O157, wzy of Escherichia coli O26, wzy of Escherichia coli O45, wzx of Escherichia coli O103, wzy of Escherichia coli O111, wzy of Escherichia coli O121, wzx of Escherichia coli O145, wzy of Escherichia coli $\mathrm{O} 157 ; 64{ }^{\circ} \mathrm{C}$ for nuc of Staphylococcus aureus; $63{ }^{\circ} \mathrm{C}$ for sobA of Streptococcus agalactiae) for $50 \mathrm{~min}$, and each experiment was repeated three times.

The Real-time LAMP with Isothermal Master Mix was also carried out on StepOne ${ }^{\mathrm{TM}}$ System (Applied Biosystems), using 0.1 $\mu \mathrm{M} \mathrm{F3}$ and B3, 0.8 $\mu \mathrm{M}$ FIP and BIP, $0.4 \mu \mathrm{M} \mathrm{LF}$, and LB, with $1 \times$ Isothermal MasterMix containing a fluorescent intercalating dye [13]. The reactions of negative controls were held at $65{ }^{\circ} \mathrm{C}$ for 50 min with real-time fluorescence monitoring, and each experiment was repeated three times.

\subsection{Bacteria Strains and DNA Extraction}

Tweleve strains used for this study (Table 2) were obtained from the Food and Bioengineering College of Xuchang University. Listeria monocytogenes ATCC19115 was cultured overnight at $37{ }^{\circ} \mathrm{C}$ in Difco ${ }^{\mathbf{T M}}$ Buffered Listeria Enrichment Broth Base (Becton, Dickinson and Company, San Jose, CA, USA) while the others in Luria-Bertani (LB) broth. Genomic DNA from these bacterial cultures was 
extracted using DNeasy ${ }^{\circledR}$ Blood \& Tissue Kit (Qiagen Inc., Valencia, CA, USA) according to the manufacturer's instructions. The genomic DNA was used to determine the detection limits of 12 in-house real-time LAMP assays as well as the commercial kit Isothermal Master Mix.

\subsection{Detection Limit Comparison}

The above described reaction mixtures of 12 in-house real-time LAMP assays were combined with serial dilutions of L. monocytogenes, Salmonella, Staphylococcus aureus, E. coli O157, E. coli O26, E. coli $\mathrm{O} 45$, E. coli O103, E. coli O111, E. coli $\mathrm{O} 121$ and Streptococcus agalactiae DNA template ranging from $0.1-100 \mathrm{pg}$, respectively, the reactions were carried out on StepOne ${ }^{\mathrm{TM}}$ System (Applied Biosystems) at described temperature for $50 \mathrm{~min}$, and each experiment was repeated four times, and the detection limits of 12 in-house real-time LAMP assays were determined.

For comparison, the detection limits of the commercial kit Isothermal Master Mix were determined by carrying out reactions according to the manufacturers' instructions using a set of serially diluted DNA template of L. monocytogenes, Salmonella, Staphylococcus aureus, E. coli O157, E. coli O26, E. coli $\mathrm{O} 45$, E. coli O103, E. coli O111, E. coli O121 and Streptococcus agalactiae DNA template ranging from $0.1-100 \mathrm{pg}$, respectively, and each reaction was repeated four times.

\section{Conclusions}

Twelve reported in-house LAMP assays for the detection of pathogenic bacteria [4-9] have been compared with the commercialized Isothermal Master Mix kit in this study. False-positive results have been observed among all 12 in-house real-time LAMP assays, and it can be concluded from our experiments that the non-specific amplification is caused by primer dimers. It is difficult to avoid primer dimers and non-specific amplification when multiple sets of primers are used in the in-house LAMP assays. This is especially true when the concentrations of primers, $\mathrm{Mg}^{2+}, \mathrm{dNTPs}$ and DNA polymerase in reaction mixtures are as high as those used in real-time PCR [14]. The concentrations of these four factors must be strictly controlled to avoid non-specific amplification in real-time PCR as well as LAMP reactions [15].

False-positive results have not been found in real-time LAMP assays with the commercialized Isothermal Master Mix kit. It is speculated that the Isothermal Master Mix kit may contain some enhancing agents, which can decrease the non-specific amplification. The detection limits for most tested pathogenic bacteria are $1 \mathrm{pg}$ DNA template, and the sensitivity of the commercial assay for E. coli $\mathrm{O} 145$ is $100 \mathrm{pg}$ DNA template. In summary, the 12 in-house real-time LAMP assays were impractical for detection of the corresponding pathogenic bacteria, while the commercial Isothermal Master Mix kit was useful for detection of the most pathogenic bacteria.

\section{Acknowledgments}

The authors would like to acknowledge the China Scholarship Council. This work was supported by Natural Science Foundation of China (31172331), NSFC-Henan Talent Training Joint Foundation (U1204330), Project for Scientific Research \& Innovation Team of Henan Universities (15IRTSTHN016), Foundation of Henan Province for Excellent Young Teachers of Colleges and Universities (2012GGJS-172), 
Project of Xuchang University for Outstanding Young Backbone Teachers, and Training Project for Outstanding Youth Backbone Personnel of Xuchang University.

\section{Author Contributions}

Y.W., F.X., W.G. and Y.Z. performed the experiments. D.W. and A.W. wrote the paper. Y.L. designed the experiments.

\section{Conflicts of Interest}

The authors declare no conflict of interest.

\section{References}

1. Notomi, T.; Okayama, H.; Masubuchi, H.; Yonekawa, T.; Watanabe, K; Amino, N.; Hase, T. Loop-mediated isothermal amplification of DNA. Nucleic Acids Res. 2000, 28 , doi:10.1093/nar/28.12.e63.

2. Nagamine, K.; Hase, T.; Notomi, T. Accelerated reaction by loop-mediated isothermal amplification using loop primers. Mol. Cell. Probe 2002, 16, 223-229.

3. Fakruddin, M. Loop mediated Isothermal Amplification (LAMP) - An Alternative to Polymerase Chain Reaction (PCR). Bangladesh Res. Publ. J. 2011, 5, 425-439.

4. Tang, M.J.; Zhou, S.; Zhang, X.Y.; Pu, J.H.; Ge, Q.L.; Tang, X.J.; Gao, Y.S. Rapid and Sensitive Detection of Listeria monocytogenes by Loop-Mediated Isothermal Amplification. Curr. Microbiol. 2011, 63, 511-516.

5. Hara-Kudo, Y.; Yoshino, M.; Kojima, T.; Ikedo, M. Loop-mediated isothermal amplification for the rapid detection of Salmonella. FEMS Microbiol. Lett. 2005, 253, 155-161.

6. Yang, H.; Ma, X.Y.; Zhang, X.Z.; Wang, Y.; Zhang, W. Development and evaluation of a loop-mediated isothermal amplification assay for the rapid detection of Staphylococcus aureus in food. Eur. Food Res. Technol. 2011, 232, 769-776.

7. Wang, F.; Jiang, L.; Yang, Q.R.; Prinyawiwatkul, W.; Ge, B.L. Rapid and Specific Detection of Escherichia coli Serogroups O26, O45, O103, O111, O121, O145, and O157 in Ground Beef, Beef Trim, and Produce by Loop-Mediated Isothermal Amplification. Appl. Environ. Microbiol. 2012, $78,2727-2736$.

8. Zhao, X.H.; Wang, J.; Forghani, F.; Park, J.H.; Park, M.S.; Seo, K.H.; Oh, D.H. Rapid Detection of Viable Escherichia coli $\mathrm{O} 157$ by Coupling Propidium Monoazide with Loop-Mediated Isothermal Amplification. J. Microbiol. Biotechnol. 2013, 23, 1708-1716.

9. Suebsing, R.; Kampeera, J.; Tookdee, B.; Withyachumnarnkul, B.; Turner, W.; Kiatpathomchai, W. Evaluation of colorimetric loop-mediated isothermal amplification assay for visual detection of Streptococcus agalactiae and Streptococcus iniae in tilapia. Lett. Appl. Microbiol. 2013, 57, 317-324.

10. Osawa, R.; Yoshida, A.; Masakiyo, Y.; Nagashima, S.; Ansai, T.; Watari, H.; Notomi, T.; Takehara, T. Rapid detection of Actinobacillus actinomycetemcomitans using a loop-mediated isothermal amplification method. Oral Microbiol. Immunol. 2007, 22, 252-259. 
11. Iwamoto, T.; Sonobe, T.; Hayashi, K. Loop-mediated isothermal amplification for direct detection of Mycobacterium tuberculosis complex, M. avium, and M. intracellulare in sputum samples. J. Clin. Microbiol. 2003, 41, 2616-2622.

12. Seki, M.; Yamashita, Y.; Torigoe, H.; Tsuda, H.; Sato, S.; Maeno, M. Loop-mediated isothermal amplification method targeting the lytA gene for detection of Streptococcus pneumoniae. J. Clin. Microbiol. 2005, 43, 1581-1586.

13. Tomlinson, J.A.; Dickinson, M.J.; Boonham, N. Detection of Botrytis cinerea by loop-mediated isothermal amplification. Lett. Appl. Microbiol. 2010, 51, 650-657.

14. Wang, D.G.; Brewster, J.D.; Paul, M.; Tomasula, P.M. Two Methods for Increased Specificity and Sensitivity in Loop-Mediated Isothermal Amplification. Molecules 2015, 20, 6048-6059.

15. Higuchi, R.; Fockler, C.; Dollinger, G.; Watson, R. Kinetic PCR analysis: Real-time monitoring of DNA amplification reactions. Biotechnology 1993, 11, 1026-1030.

Sample Availability: Not available.

(C) 2015 by the authors; licensee MDPI, Basel, Switzerland. This article is an open access article distributed under the terms and conditions of the Creative Commons Attribution license (http://creativecommons.org/licenses/by/4.0/). 